Doi: $10.15863 /$ TAS

International Scientific Journal Theoretical \& Applied Science

p-ISSN: $2308-4944$ (print)

e-ISSN: 2409-0085 (online)

Year: 2015

Issue: 01

Volume: 2

Published: 30.01 .2015

http://www.T-Science.org
Elena Valentinovna Holovina

Docent

Kremenchug University of Economics, Information Technology and Management,

Ukraine

elenholz@gmail.com

SECTION 7. Mechanics and machine construction.

\title{
VEHICLE REACTION LAG TO THE CHANGE OF THE STEERING- WHEEL ANGLE
}

Abstract: An analytical method for determining the single-vehicle and two-link trains reaction lag time to the change of the steering-wheel angle is suggested that allows to affect the readability level of the new vehicle just at the designing stage.

Key words: lag time, whirl angle, longitudinal size of the tire imprint.

Language: English

Citation: Holovina EV (2015) VEHICLE REACTION LAG TO THE CHANGE OF THE STEERINGWHEEL ANGLE. ISJ Theoretical \& Applied Science 01 (21): 45-48. doi: http://dx.doi.org/10.15863/TAS.2015.01.21.7

The vehicle follows a curved trajectory most of the time. Turning depends on its readability level and stability, it is important to know vehicle reaction time to the change of steering wheel angle. Scientists in their papers $[1,2,3,4,5,6]$ settle this problem by using a sufficiently large experimental data set.

The paper proposes an analytical method for determining lag time of the single-vehicle and twolink trains reaction to the change of the steeringwheel angle that allows to affect the readability level of the new vehicle just at the designing stage.

Vehicle lag time $t_{3}$ can vary greatly when the vehicle is moving due to its inertia, tyres flexibility, steering and changes in a wide range of coupling properties of the tire support surface. The size and weight of the vehicle, characteristics of unsteady breakaway, wheel axis slip angles ratio, their number and location, inertia of the moving masses moments, motion modes and turns affected on time $t_{3}$ value.

The article proposes to use elastic theory of the tire relative to the vertical axis for determining the lag time [7]. Whirl angle of the tire relative to vertical axis:

$$
\theta_{\rho i}=\frac{a_{i}+2 \cdot x}{4 \rho_{i}}
$$

$a_{i}$ is the longitudinal size of the tire imprint at defined time of going into corner, $\mathrm{m}$; $x$ is steering axis shift of the imprint relative to its center, $\mathrm{m}$;

$\rho_{\mathrm{i}}$ is curvature radius of the tire trajectory at defined time of going into corner, $\mathrm{m}$;

Equation (1) was obtained of the condition that maximum whirl angle of the tires for contact mark of this moment will be when the wheel center travel over distance of arc with radius $\rho_{\mathrm{i}}$ :

$$
S=\left(a_{i}+2 \cdot x\right) \text {. }
$$

During this period of time it is formed ultimate current of resistance to curvilinear motion in the contact mark of this moment.

In order to make the vehicle to move in a new path as a self-adjusting system in the plane of the road it is necessary to form new yaw moment, which must be greater or equal to sum of resistance moments to curvilinear motion. For this purpose the wheel center have to travel over the distance of the arc of radius $\rho_{\mathrm{i}}$. It is necessary time interval for fulfilment this condition:

$$
t_{3}=\frac{S}{V_{a i}}=\frac{a_{i}+2 \cdot x}{V_{a i}}=\frac{a_{i}+2 \cdot V_{a i} \cdot \Delta t}{V_{a i}},
$$

$\Delta t$ is the period of time during which the process of turning was considered.

The dependence (3) is obtained for a single vehicle and takes into account the main factors that influence the vehicle reaction lag time $t_{3}$, because the size of the contact mark depends on the load 
variation on the wheel, the radial tires stiffness; vehicle speed when entering the turn (at constant acceleration-pedal position) depends on the resisting moments, which in turn depends on loading of tyre, lateral and angular stiffness, radius of the trajectory curvature and radii depend on the mode of motion and the ratio of wheels slip angles, vehicle design parameters.

The maximum lag time of a three-axle vehicle with base $l_{T}$ rear rigid bogie at the steady mode of motion:

$$
t_{3}=t_{3 \max }=\frac{a_{i}+2 \cdot x}{V_{a i}}=\frac{a_{i}+2 \cdot \frac{l_{T}}{2}}{V_{a i}}=\frac{a_{i}+l_{T}}{V_{a i}} .
$$

The maximum lag time is determined when turning rate of the contact mark is more than turning rate of the internal steering wheel about the kingpin axis:

$$
\dot{\theta}_{\rho i}>\dot{\alpha}_{1 b}
$$

When considering two-link train lag time of the truck $t_{3 \mathrm{~T}}$ it is determined by using the dependence (3), which is obtained from the condition that the yaw moment created by steering wheels of the truck over a period of time $\Delta t$ will balance the resisting moment to train turning. As soon as this equality is fulfilled, the truck will move along the trajectory set by steering wheels by the driver taking into account slip angle at each new turn of steering wheel. The same process occurs for the semitrailer.

Based on the above it can be written dependence for determining the lag time of the semi-trailer $t_{3 \Pi}$ on the steering wheel, considering that $t_{3 п}$ functionally depends on the lag time of the truck $t_{3 \mathrm{~T}}$ :

$$
t_{3 \Pi}=t_{3 T} \frac{V_{A i}}{V_{A \Pi \mathrm{i}}},
$$

$V_{A \Pi 1}$ - speed of semitrailer:

$$
\mathrm{V}_{A i} \cdot \cos \psi_{i}=\mathrm{V}_{A i} \cdot \cos \left(\sum_{1}^{i} \frac{V_{A i} \cdot \Delta t}{\rho_{T i}}\right)
$$

Substitute (7) in (6) we receive:

$$
t_{3 \Pi}=\frac{t_{3 T}}{\cos \left(\sum_{1}^{i} \frac{V_{A i} \cdot \Delta t}{\rho_{T i}}\right)} .
$$

Determining of the vehicle reaction of longitudinal axis lag time will allow to establish the possibility of various tests performance at the design stage. As experience shows during operation it is often need swerve of suddenly appearing obstacle. This maneuver is similar to "elk test" which the vehicle carries out during steering and stability tests. The "elk test" is made during overtaking, in preparation for turning, at swerve of suddenly appearing obstacle.

Under the terms of maneuver the driver, when crossing of the vehicle by front wheels of borders between acceleration and start areas of the marked corridor quickly removes a foot from a gas pedal and starts turning the steering wheel for maneuver performance. The condition was accepted that accelerator pedal position at coming into corner remains constant. It will be a guarantee that the vehicle will fall within the marked corridor. If the vehicle falls within the marked corridor at constant position of acceleration pedal, so at removed foot from the pedal the vehicle guaranteedly will fall within maneuver zone as the vehicle speed decreases quicker, than at the constant position of acceleration pedal.

The vehicle reaction lag time of the steering wheel was defined at tracing of vehicle KRAZ6322 motion when performance "elk test".

Track parameters were defined by means of the method offered in the paper [9].

Vehicle KRAZ-6322 has size of longitudinal wheel print $\mathrm{a}_{\mathrm{i}}=0,355 \mathrm{~m}$.

Standard values of vehicle speed of the category N3 with gross weight more than $20 \mathrm{t}$ when performing test "elk test $\mathrm{S}_{\Pi}=20 \mathrm{~m}$ " $54 \mathrm{~km} / \mathrm{h}$, when performing maneuver "elk test $\mathrm{S}_{\Pi}=16 \mathrm{~m}$ " - 44 $\mathrm{km} / \mathrm{h}$.

At steering and stability tests it is made the quickest possible steering input in the standard position with angular speed not less than 400 degree/s that corresponds to 6,978 is radian/s.

It was accepted $\omega_{\mathrm{pK}}=7 \mathrm{radian} / \mathrm{s}$.

$$
\dot{\alpha}_{1_{g}}=\frac{\omega_{p \kappa}}{i_{p M}}=\frac{7}{23,6}=0,296 \mathrm{paz} / \mathrm{c} .
$$

The tracing was when performing maneuver with speed $=54 \mathrm{~km} / \mathrm{h}$. For obtaining more exact parameters was chosen the period $\Delta t=0,05 \mathrm{~s}$.

The real radius of track curvature can be determined on classical dependence:

$$
\rho_{\partial i}=\frac{L}{\operatorname{tg}\left(\alpha_{i}^{\circ}-\theta_{k i}^{\circ}\right)}-\frac{B}{2}
$$


$\theta_{\text {кi }}$-wheel slip angle.

The vehicle reaction lag time of the steering wheel without steering drive rigidity in accordance with (3):

$$
t_{3}=\frac{a_{i}+2 V_{A i} \cdot \Delta t}{V_{A i}}=\frac{0,355+2 \cdot 15 \cdot 0,05}{15}=0,124 \mathrm{~s} .
$$

During lag time the vehicle will pass the way:

$$
S_{3}=V_{A i} \cdot t_{3}=15 \cdot 0,124=1,86 \mathrm{~m} \text {. }
$$

Thus, due to the vehicle reaction lag time of the steering wheel to the change of steering wheel position the motion track will move towards performance of maneuver on $1,86 \mathrm{~m}$ that significantly changes geometrical maneuver parameters.

Taking into account time $t_{3}$ the path length on which the driver has to fall within the corridor $\mathrm{S}_{\Pi}=20 \mathrm{~m}$ will change and it will be equal:

$$
\begin{gathered}
S^{*}=S_{\Pi}-V_{A i} \cdot t_{3}, \\
S^{*}=20-15 \cdot 0,123=18,155 \mathrm{~m} .
\end{gathered}
$$

If we know the motion speed and path length $S^{*}$ during which the vehicle has to fall within the corridor "elk test $S_{\Pi}=20 \mathrm{~m}$ " it is possible to define test performance time:

$$
t^{*}=\frac{S^{*}}{V_{A i}}=\frac{18,155}{15}=1,21 \mathrm{~s} .
$$

In fig. 1 it is presented the motion track of vehicle KRAZ-6322 when performing maneuver "elk test" taking into account the vehicle reaction lag time of the steering wheel.

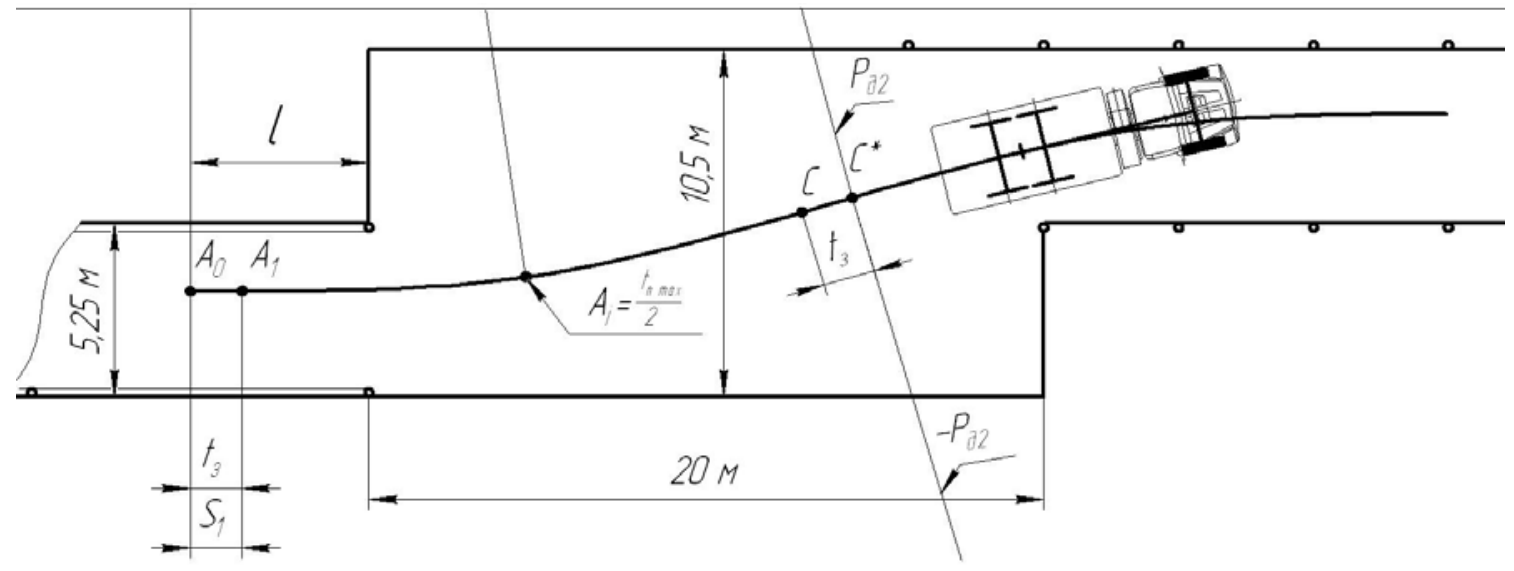

Figure 1 - The trajectory of the KrAZ-6322 when performing a maneuver permutation $\mathrm{S} n=\mathbf{2 0} \mathrm{m}$ at speed of $\mathrm{Va}=54 \mathrm{~km} / \mathrm{h}$.

The knowledge of the vehicle reaction lag time of the steering wheel will allow significantly to specify parameters of performance of various maneuvers.
Thus, using the elastic theory of the tyre relative to vertical axis analytical dependences determining the single-vehicle and two-link trains reaction lag time to the change of the steeringwheel angle were obtained and affecting factors were fixed.

\section{References:}

1. Boldyrev AG (2006) Method of energy consumption assessing in the operation allwheel steering of multiaxle wheeled vehicles at the design stage: abstract of thesis Doctor of Science dissertation.: specialization 05.05 .03
Wheeled and tracked vehicles / A. Boldyrev Moscow, 2006. - 16.

2. Litvinov AS (1971) Readability and stability of the vehicle / A. S. Litvinov. - Moscow: Mashinostroenie, 415. 
3. Shadrin SS (2009) The method of calculation assessment of readability and stability of the vehicle on the basis of field tests results.: abstract of thesis Doctor of Science dissertation.: specialization 05.05.03 Wheeled and tracked vehicles / S. S. Shadrin - Moscow, 2009. - 24.

4. Ostashevskii SA (2014) Research of the system ability "car-driver-road" to road diversion of unexpected obstacles / S. A. Ostashevskii. - Naukovi Pratsi VNTU. - 2014. № 2. - pp. 1 - 7.

5. Khachaturov AA (1982) Calculation of operational parameters of the vehicle and trailer / Khachaturov A. A. - Moscow: Transport, 1982. - 264.

6. (1976) The dynamics of the system road - tyre - vehicle - driver / Khachaturov A. A., Afanasiev, C. L., Vasiliev V. S., and others Moscow: Mashinostroenie, 1976. - 535.
7. Redchits VV (1974) About the phenomenon of relative turning of the contact mark of the moving wheel / V.V. Redchits /Automobile industry. - 1974. № 3. - pp. 28 - 30.

8. Golovina EV (2008) Dynamics of tri-axle vehicle at going into corner / E. V. Golovina / Advanced technologies. Scientific bulletin of KUEITU. - 2008. - №4 (22). - pp. 185 - 189.

9. Redchits VV (2011) Research of three-axis vehicle driving at maneuver "elk test" / Redchits V. V., Holovina O. V, Korablev O.F.//Advanced technologies. Scientific bulletin of KUEITU. - 2011. - No. 4(34) pp. $80-87$.

10. Redchits VV (2014) Relationship three theories of pneumatic tyre / Redchits V. V., Holovina O.V. ISJ Theoretical \& Applied Science. - 2014. - № 3(11) - pp. 31 - 34. doi: http://dx.doi.org/10.15863/TAS.2014.03.11.6 